\title{
UNCERTAINTIES IN ATTENUATION RELATIONS FOR NEW ZEALAND SEISMIC HAZARD ANALYSIS
}

\author{
G. H. McVerry*
}

\begin{abstract}
SUMMARY
Probabilistic techniques for seismic hazard analysis have come into vogue in New Zealand for both the assessment of major projects and the development and review of seismic design codes. However, there are considerable uncertainties in the modelling of the strong-motion attenuation, which is necessarily based largely on overseas data. An excellent agreement is obtained between an average $5 \%$ damped response spectrum for New Zealand alluvial sites in the 20 to $59 \mathrm{~km}$ distance range and 5.4 to 6.0 magnitude class and that given by a Japanese model. Unfortunately, this corresponds to only about half the amplitude levels of 150 year spectra relevant to code design. The much more rapid decay of ground shaking with distance in New Zealand has led to a considerable modification based on maximum ground acceleration data from the Inangahua earthquake of the distance-dependence of the Japanese response spectra model. Less scatter in New Zealand data has resulted in adopting a lower standard deviation for the attenuation model, which is important in reducing the considerable "probabilistic enhancement" of the hazard estimates. Regional differences in attenuation shown by intensities are difficult to resolve from the strong-motion acceleration data, apart from lower accelerations in Fiordland.
\end{abstract}

\section{INTRODUCTION}

Recently there has been considerable effort in New Zealand devoted to seismic hazard analysis for calculating the level of earthquake shaking as a function of return period both for specific major projects and for more general assessments for the development and revision of seismic design codes. Since 1980, studies concerned with New Zealand as a whole have been produced by Auckland University [13], Canterbury University $[17,19,20]$, and the DSIR $[25,26]$. Most of the applications to specific sites have used the results of these studies or the earlier one by Bentley [2], sometimes combined with more detailed local geographical data.

The estimation of the seismic hazard in all these studies has involved the combination of two components: a seismicity model, which gives the rate of occurrence of earthquakes as a function of magnitude and location, and an attention relationship, often expressed in probabilistic form, which predicts the strength of shaking as a function of magnitude and distance, and possibly taking into account site conditions and regional variations in attenuation as well. Some of the problems involved in estimating seismicity have been discussed recently by Smith [24]. This paper is concerned with the uncertainties involved in the attenuation part of the problem.

There are a number of parameters which may be used to quantify the strength

* Scientist, Engineering Seismology

Section, PEL, DSIR. of earthquake shaking at a site: intensities, maximum ground accelerations and response and Fourier spectra are the most common. There are by far the most data for intensities, but these are of limited use for engineering design. Conversely, response spectra are directly relevant to specifying design loads, but there are few available for New Zealand earthquakes. Thus modelling of response spectra must be based heavily on overseas data, verified and modified where possible with New Zealand spectra, with little scope for accounting for any regional variations within the country. The alternative approach of using correlations with intensities to convert New Zealand intensity models incorporating regional variations in attenuation to maximum ground acceleration or acceleration response spectrum models is a process which compounds the uncertainties [7]. The scatter inherent in the data and the uncertainty of the mean-value correlations is apparent from the plot of New zealand maximum ground accelerations recorded by the strong-motion network as a function of intensity in Fig. 1, which also shows the comparison of the accelerationintensity relations obtained from a leastsquares fit of the data and the bounds used by the Seismological observatory.

The results of the various seismic risk studies of New Zealand have generally been presented as maps showing the strength of shaking throughout the country for various return periods. These maps allow results for any site of interest to be extracted very simply, although it should be noted that the veneer of fine geographical resolution suggested by the detailed modelling of seismicity is not matched by the much broader-brush approach of the 


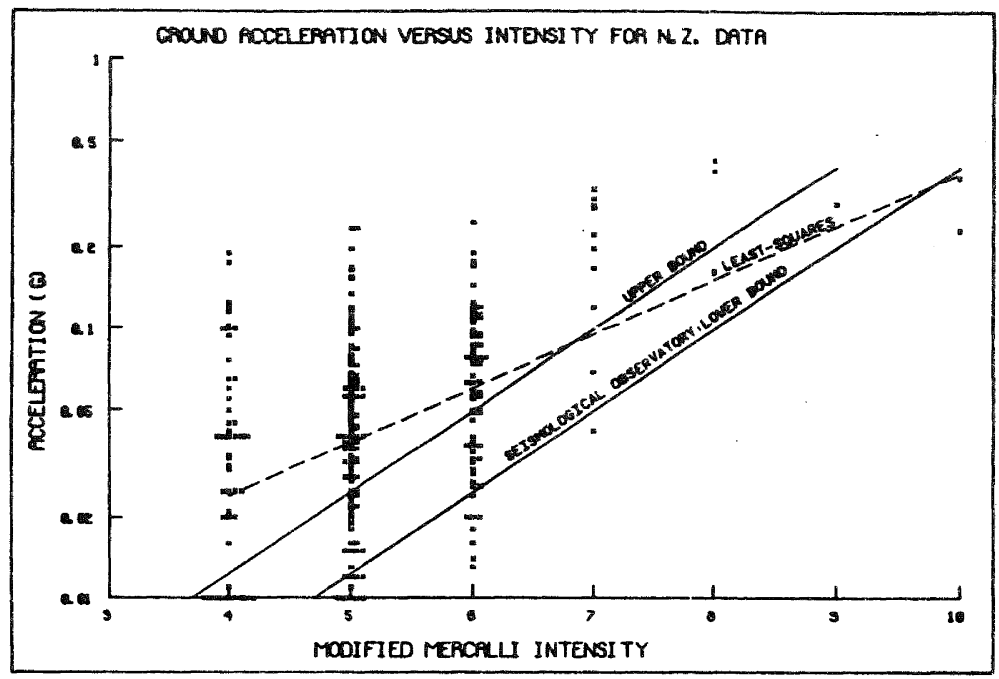

FIG. 1 : ACCELERATION-INTENSITY DISTRIBUTION FOR RECORDS FROM THE NEW ZEALAND STRONG-MOTION ACCELEROGRAPH NETWORK.

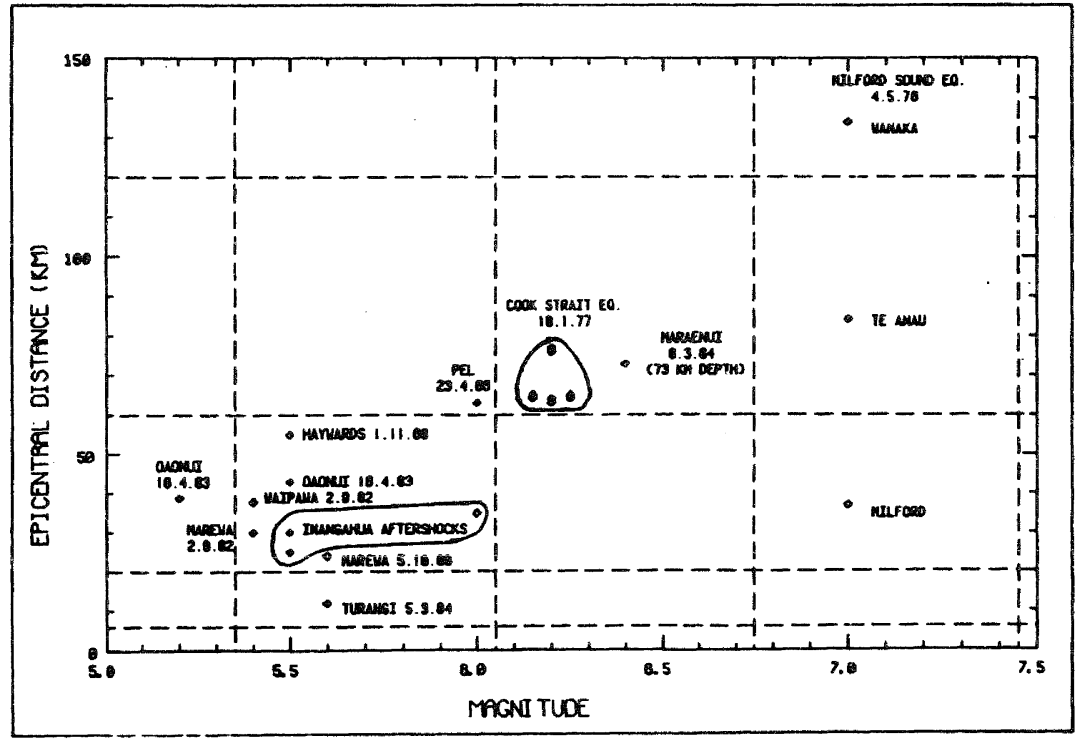

FIG. 2 : DISTRIBUTION OF NEW ZEALAND RESPONSE SPECTRA AGAINST THE MAGNITUDEDISTANCE BOUNDARIES OF THE KATAYAMA CLASSES.

attenuation modelling. Moreover, the prudent engineer involved with a major project should do more than accept the results at face value. Often the results are sensitive to small variations in parameters whose values are poorly known, and to the placement of boundaries between active and relatively inactive seismic zones. The degree of conservatism at each stage should be assessed. High estimates of seismicity may have been combined with conservative attenuation models, or conversely an optimistic view of the seismicity combined with a "deterministic" mean-value attenuation relationship, while the true hazard lies between that calculated from these extreme approaches.

Use should be made of local data which may be available or become available as a result of site investigations. The nationwide studies have necessarily been restricted to data on a regional scale. Detailed studies of a fault adjacent to a site of local soil or topographic conditions may alter the conclusions on the seismic hazard considerably. Similarly, some areas may be affected by "anomalous" earthquakes, such as repeated swarms or unusually high intensities for low magnitudes, which may affect the level of shaking for short return periods lof the order of 100 years or less) significantly.

Intensive reviews of the results of the seismic risk analyses for such major projects as the clyde Dam and for the revision of the NZS 4203 Loadings Code have revealed problems with various seismicity and attenuation models currently in use in New Zealand, and also in some features of the probabilistic approach. Smith and Berryman [26] have attempted to improve troublesoine features of the earlier 
seismicity models. This paper addresses some of the problems relating to the attenuation models and the probabilistic approach, overlapping to some extent with the review of Berrill [3]. It is based largely on the work of the SANz seismic Risk subcomittee for the revision of NZS 4203 , and concentrates on the attenuation model used by it, but is relevant also to seismic hazard studies performed to prepare guidelines for bridge design $[3,4,5,21]$, petrochemical plant design [14] and major projects. A number of modifications have been proposed to the original Japanese model for application in New Zealand. The changes highlight some of the weaknesses of the model which tend to be hidden by the sophisticated mathematical framework of probabilistic seismic risk analysis.

2. UNIFORM RISK SPECTRA USING THE MODIFIED KATAYAMA ATTENUATION MODEL

The SANZ Seismic Risk subcomittee has taken the approach of deriving uniform risk 5\% damped elastic response spectra for various return periods (e.g. 50 years, 150 years, 450 years) for the whole of New Zealand as the basis of their recommendations for code seismic loading levels. A 150 year return period is considered appropriate for normal design. The code design spectra will usually be reduced from the elastic spectra to allow for ductility.

The uniform spectra have been derived by combining the Smith and Berryman seismicity model with a probabilistic attenuation model for $5 \%$ damped response spectra based on the model derived from Japanese data by Katayama 11]. This model was selected because of similarities between the tectonic environment of Japan and New Zealand, and because preliminary investigations at Canterbury University showed that this model represented New Zealand spectra better than others by Bentley [2] based on a combination of Japanese and US data supplemented by strong records from other parts of the world, and McGuire [12] based on Western US data. The Katayama attenuation model has been modified, first in the work by Peek [19] and Mulholland [17] at Canterbury University, and later in the light of further New Zealand data and on consideration of the implications of some features of the model by the committee itself.

The Katayama model predicts the median (corresponding to the mean of the log) $5 \%$ damped spectral acceleration $\overline{\mathrm{SA}}(\mathrm{T})$ as the product of a magnitude factor, distance factor and ground class factor for 18 spectral periods $T$ ranging from 0.10 to 4.0 seconds. The values of these factors are specified for five magnitude classes five distance classes and four ground condition classes as listed in Table 1 , giving one hundred "cells" in all. Sufficient New Zealand response spectra data are available for detailed verification of the model for only one of these cells, with checks with a few spectra for some of the other cells. The spectral accelerations $\mathrm{SA}(\mathrm{T})$ are assumed log normally distributed, as indicated by the Japanese data from which the model was derived, with a common standard deviation $\sigma$ for $\log _{10} \mathrm{SA}(\mathrm{T})$ for all periods and classes.

A number of modifications have been found necessary: (a) to correct for the frequency response characteristics of Japanese accelerographs, (b) to reduce the standard deviation of the original model which is higher than in most overseas studies and also appears higher than that indicated by New Zealland data; and (c) to produce more rapid attenuation with distance as seems appropriate for New Zealand. A further magnitude-and distancedependent correction factor has been introduced for Fiordland to produce lower spectral accelerations there than for the rest of the country, in agreement with assigned intensities and measured peak ground accelerations. The problem of "probabilistic enhancement", that is the increase in the spectral acceleration for a given return period calculated from the probabilistic attenuation model over that given by a "deterministic" model using the mean value attenuation function, has been particularly vexing and a number of strategies are being investigated to counter its effects. An irritating feature of the model is that the various magnitude, distance and ground class factors are exactly as derived from the least-suqares fitting of the Japanese data, resulting in factors which are not smooth functions of distance, magnitude and period.

\subsection{Comparison of the Modified Katayama Model and New Zealand Spectra}

A major problem in verifying the Katayama model with New Zealand data is the scarcity of New Zealand spectra. Response spectra have been calculated for only 23 New zealand records produced by shallow earthquakes at ground or building basement sites. The distribution of these records as a function of magnitude and distance is shown in Fig. 2 against a grid giving the boundaries of the Katayama classes. This is an update of a figure by Muliholland. It is fortunate that 7 of the records (i.e. I4 horizontal components) lie within the same cell of the Katayama model (20-59 km epicentral distance, magnitude 5.4-6.0, alluvial sites). These records are listed in Table 2. This provides the opportunity to test the modified Katayama model against the New Zealand data for at least one distance class-magnitude class-ground class cell, with the warning that the 7 records are from only 4 sites, as 3 are from Inangahua aftershocks at Westport, and 2 are from the Marewa site at Napier. Mulholland has previously tested individual spectra against the Katayama model.

Figure 3 compares the average and \pm 2 standard deviation values of $\log _{10} \mathrm{SA}(\mathrm{T}$, $5 \%$ of the 14 New Zealand spectra from this magnitude-distance-ground condition cell with the curves predicted by the Katayama model as modified by Mulholland to account for the frequency response of Japan accelerographs. For the New Zealand spectra, $\sigma$ has been calculated individually for each period, giving a modified shape to the $\pm 2 \sigma$ curves from the average spectrum. The Katayama $\pm 2 \sigma$ curves are 
TABLE 1 : MAGNITUDE, DISTANCE AND GROUND CONDITION CLASSES OF KATAYAMA MODEL

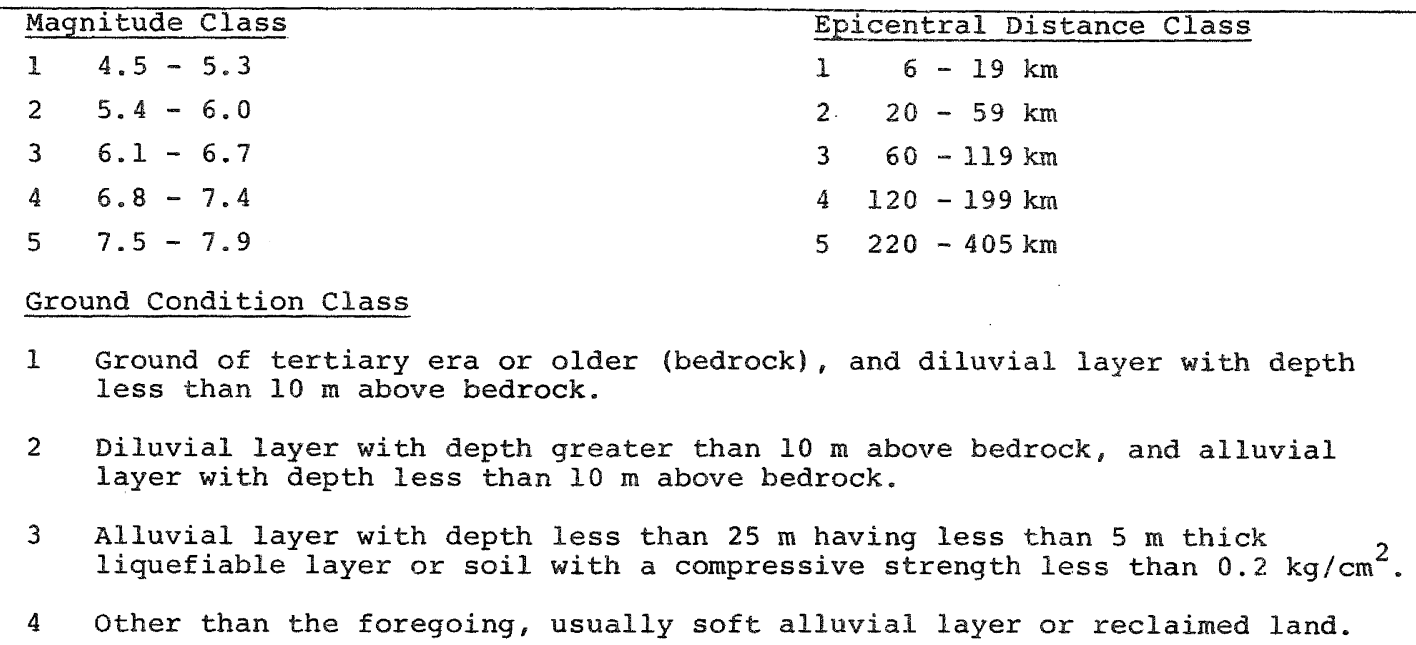

TABLE 2 : NEW ZEALAND RESPONSE SPECTRA RECORDS FOR COMPARISON WITH KATAYAMA MODEL

\begin{tabular}{|l|l|l|l|l|c|}
\hline $\begin{array}{c}\text { PEL } \\
\text { Identifier }\end{array}$ & Earthquake & $\begin{array}{l}\text { Event } \\
\text { Time }\end{array}$ & Magnitude & Site & $\begin{array}{l}\text { Epicentral } \\
\text { Distance }\end{array}$ \\
\hline E68051A4 & $\begin{array}{l}\text { Inangahua } \\
\text { aftershock }\end{array}$ & $\begin{array}{l}24 \text { May } 68 \\
(20: 57 \text { UT) }\end{array}$ & 6.0 & Westport & $36 \mathrm{~km}$ \\
E68051A7 & $\begin{array}{l}\text { Inangahua } \\
\text { aftershock }\end{array}$ & $\begin{array}{l}25 \text { May } 68 \\
(23: 49 \text { UT) }\end{array}$ & 5.5 & Westport & 25 \\
E68051AC & Inangahua & 14 June 68 & 5.5 & Westport & 30 \\
E80027Cl & Napier & 5 Oct. 80 & 5.6 & Marewa & 26 \\
E82032A1 & Napier & 2 Sept. 82 & 5.4 & Waipawa & 37 \\
E82027Cl & Napier & 2 Sept. 82 & 5.4 & Marewa & 29 \\
E83106A2 & Taranaki & 16 April 83 & 5.5 & Oaonui & 42 \\
\hline
\end{tabular}

TABLE 3 : SENSITIVITY OF PROBABILISTIC ENHANCEMENT TO PARAMETERS $b, c$ and $\sigma$

\begin{tabular}{|c|c|c|c|c|}
\hline \multicolumn{3}{|c|}{$\begin{array}{l}\text { Rate Enhancement } \\
\operatorname{Exp}\left[2.3^{2} b^{2} \sigma^{2} / 2 c^{2}\right]\end{array}$} & \multicolumn{2}{|c|}{$\begin{array}{l}\text { Acceleration Enhancement } \\
\operatorname{Exp}\left(2.3^{2} b \sigma^{2} / 2 c\right]\end{array}$} \\
\hline \multirow{4}{*}{$\begin{aligned} \mathrm{b}= & 0.9 \\
& 1.1\end{aligned}$} & \multicolumn{2}{|c|}{$c=0.25$} & \multicolumn{2}{|c|}{$c=0.25$} \\
\hline & $\sigma=0.23$ & 0.30 & $\sigma=0.23$ & 0.30 \\
\hline & 6.2 & 22 & 1.66 & 2.36 \\
\hline & 15 & 100 & 1.85 & 2.86 \\
\hline \multirow{3}{*}{$\begin{array}{r}b=0.9 \\
1.1\end{array}$} & \multicolumn{2}{|c|}{$c=0.40$} & \multicolumn{2}{|c|}{$c=0.40$} \\
\hline & 2.03 & 3.3 & 1.37 & 1.71 \\
\hline & 2.88 & 6.1 & 1.47 & 1.92 \\
\hline
\end{tabular}




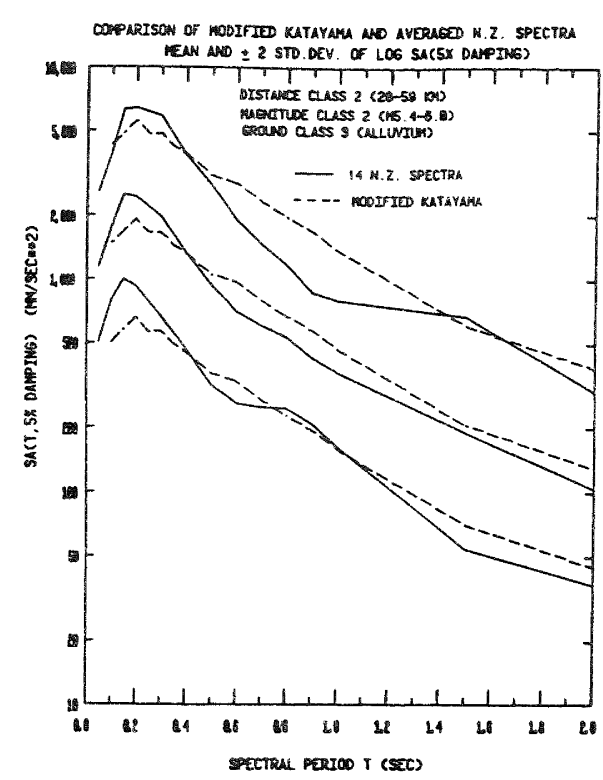

FIG. 3 : COMPARISON OF MULHOLLAND'S MODIFIED KATAYAMA MODEL SPECTRA AND AVERAGED NEW ZEALAND RESPONSE SPECTRA FOR THE SAME DISTANCE-MAGNITUDE-GROUND CONDITION CLASS.

just shifted versions of the mean curve as the same $\sigma \quad(=0.233)$ has been used for all periods.

The agreement between the average New Zealand and modified Katayama curves is remarkable. The $\pm 2 \sigma$ curves are also in good agreement, provided the reduced value of 0.233 adopted by Mulholland rather than Katayama's original value of 0.3 is used. This provides confidence that the modified Katayama model represents New Zealand data well, at least for the magnitude-distance-ground condition class which has provided most New Zealand data to date.

From this study it appears that the standard deviation can be reduced further, as the overall value from the 14 New lealand spectra is 0.204 , with values for individual periods ranging from 0.154 to 0.272 . However, Berrill [6] warns that the New Zealand data set lacks records of large magnitude events at close distance, which would increase the scatter. Using a larger New Zealand data set of 22 horizontal components, from several magnitude-distance-ground condition classes. he found a mean standard deviation of 0.254 of the logarithmic residuals from the Katayama model. Furthermore, overseas data give some indication of an increasing standard deviation for longer spectral periods, and as shaking at long periods is caused mainly by large magnitude events missing from the New Zealand data, Berrill suggested that period-dependent standard deviations obtained from the combined New Zealand and Japanese data should be used. This suggestion has been adopted by the SANZ Seismic Risk committee, with values of $\sigma$ varying from 0.280 for 0.10 second period to 0.320 for natural periods 1.0 seconds or greater.

It is unfortunate however that the level of the mean spectrum for this class is only about half that calculated for the more seismically active regions of New Zealand for a 150 year return period. It is desirable to verify the Katayama spectra at levels nearer that of the uniform risk spectrum for code return periods.

Another point is that in calculating uniform risk spectra for different locations around New Zealand, Peek and Mulholland have taken the basic spectrum as that for rock, Katayama's ground class I. The form of the model allows uniform risk spectra, as well as those for given magnitude and distance classes, for other ground classes to be derived simply from the corresponding rock spectrum by multiplying by a ground class factor which depends only on spectral period and not on magnitude, distance or return period. It would seem more sensible to calculate the basic spectrum for the ground conditions which are most commonly encountered and from which the bulk of both the New Zealand and Japanese data was obtained, that is alluvium (class III) rather than rock (class I). This has the further advantage that it retains consistency with the type of ground conditions associated with the records that have been used previously in New Zealand to derive smoothed reponse spectra, such as Skinner's

Fig. 15 [22] derived from the El centro 1934 and 1940, Olympia 1949 and Taft 1952 records. Katayama's rock spectra are strongly peaked at about 0.20 seconds, with a rapid dropoff at longer periods. The peaks are broadened considerably when the conversion factors between rock and alluvium are applied, giving a spectral shape more familiar to New Zealand engineers. There has been considerable scepticism about the highly-peaked nature of the Katayama rock spectra. However, the spectra from the Maraenui record of the recent Motu river earthquake (March 8, 1984) recorded on the firm alluvium of an old terrace are even more peaked than Katayama's rock spectra, with a peak $5 \%$ damped spectral acceleration of $1 \mathrm{~g}$ at 0.2 seconds natural period dropping to $0.1 \mathrm{~g}$ at 0.4 seconds.

With the Katayama model verified for the one distance-magnitude-ground condition cell, it remains to establish how well it applies for other distances, magnitudes and ground conditions. Regional variations in attenuation, which seem likely to be important in Fiordland and possibly in the Hawkes Bay region, have also be the incorporated.

\subsection{Attenuation with Distance}

The variation around the country in the peak spectral accelerations for a given return period is less than that expected on the basis of the results calculated for intensities using the same seismicity model but an attenuation model developed from New Zealand data. The different levels of seismicity reflected in the variation of the intensities are much less apparent in the spectral accelerations. One possible 
explanation is that the contribution of distant earthquakes is over-estimated, making all areas of the country subject to the influence of regions of high seismicity. This suspicion is supported by a cursory examination of catalogues of Japanese strong-motion data, which have a greater relative frequency of records from distant events than occurs in New Zealand, even allowing for the many more large magnitude events in Japan. This suggests a more rapid attenuation with distance in New Zealand than in Japan. Katayama found that his model gave smaller accelerations at short distances but a much less rapid falloff of spectral accelerations with increasing distance than predicted by a model derived from Californian data by Trifunac and Anderson [27]. This point was also noted by Bentley [2] in comparing Japanese and western us spectra. It is thus important to determine the rate of attenuation with distance appropriate to New Zealand.

Unfortunately, there are insufficient New Zealand spectra to determine the attenuation of spectral accelerations with distance directly. Instead, the attenuation of peak ground accelerations was considered, and the results adapted to spectral accelerations. The data used for this study were the 161 records (of the total of 1059 from the New Zealand strongmotion accelerograph network) which exceed $0.02 \mathrm{~g}$ and were obtained from ground or building basement sites in shallow events of magnitude 4.5 or greater.

Attempts to derive a Katayama-type multiplicative factor model from the 161 peak acceleration data points were unsatisfactory because of insufficient data in the shortest and longest distance ranges and the largest magnitude range, and because of a great scatter in the data in individual magnitude-distance cells. Another approach was to fit a model of the form

$$
\log a=C_{0}+C_{M}^{M}-C_{L D} \log D
$$

This was also unsatisfactory because the least-squares normal equations for estimating the parameters $C_{O}, C_{I D}, C_{M}$ and were nearly singular because of the' limited ranges of magnitude and log distance over which the data had been obtained. This problem must apply also for the most overseas data sets but is rarely acknowledged.

There have been suggestions that better parameter estimates can be obtained by a two-stage least-squares fit, first lumping the $C_{0}+C_{M} M$ terms into a single term $C_{i}$ for each earthquake, determining $C_{L D}$ and the $C_{i}$, and then determining $C$ and $C_{M} L$ by fitting the $C_{i}$ from all the earthquakes [10]. This app roach requires a data set containing several records over a reasonable spread of distances for each earthquake. This data is not available for New Zealand. The only shallow event which has produced more than three records over a broad spread of distances is the magnitude 7.1 Inangahua earthquake of 1968.
From the Inangahua earthquake there are 12 scratch-plate records ranging from epicentral distances of $27 \mathrm{~km}$ at Murchison to $174 \mathrm{~km}$ at Picton. A $\log -10 \mathrm{~g}$ plot of acceleration a versus epicentral distance $D$ is shown in Fig. 4. It is remarkable that 9 of the 12 points lie virtually on a straight line. The slope $\gamma$ is -1.1 , implying a power law dependence of acceleration on distance, a $\alpha \mathrm{D}^{-1.1}$. The slope of -1.1 is plausible, but not so well constrained, for other shallow New zealand earthquakes with less data. These events include Westport 1962, Seddon 1966, Maruia earthquake of 1966, for which the slope from 3 points, 2 at similar distances, is about -2.1 .

The distance dependence of the Katayama model at short periods corresponds to a slope of -0.5 , a much less rapid attenuation. A plot of the Katayama distance factors for a number of periods is shown in Fig. 5, showing the well-known result that long-period components of earthquake waves attenuate much less rapidly than short-period components. With the dependence of the attenuation rate on period it is problematical how to apply the $\gamma=-1.1$ result for peak accelerations from the Inangahua earthquake to the attenuation model for response spectral accelerations. The approach below was arrived at in discussion with W.D. Smith of the Seismological observatory.

It was decided to retain the feature of the Katayama model that the distance factor is independent of period for the longest distance class of $200-405 \mathrm{~km}$, but with a new reduced value. The distance factors for the $20-59 \mathrm{~km}$ class were retained, apart from some slight smoothing as a function of spectral period, in light of the comparison of the predicted spectra and the 14 New Zealand spectra. The value of $\gamma=-1.1$ was taken as the most rapid attenuation with distance for any spectral period, and was applied at a period of

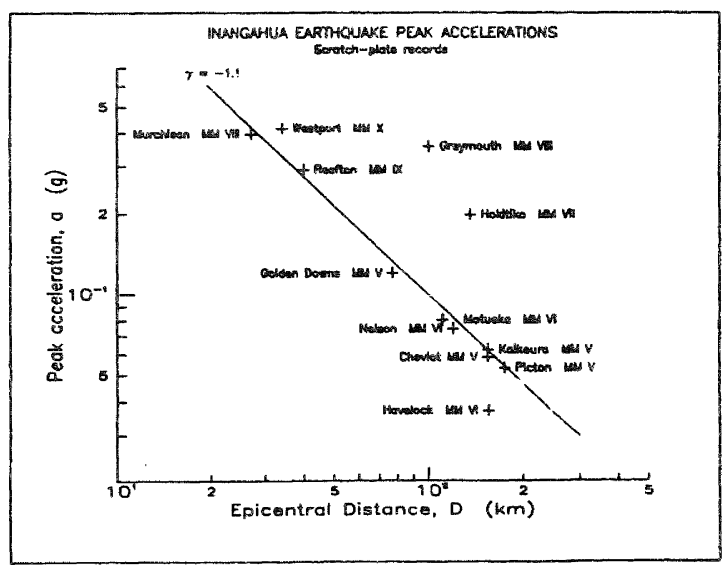

FIG. 4 : PEAK ACCELERATION READINGS FROM SCRATCH-PLATE RECORDS OF THE INANGAHUA EARTHQUAKE, AND THE D-1.1 FIT. 


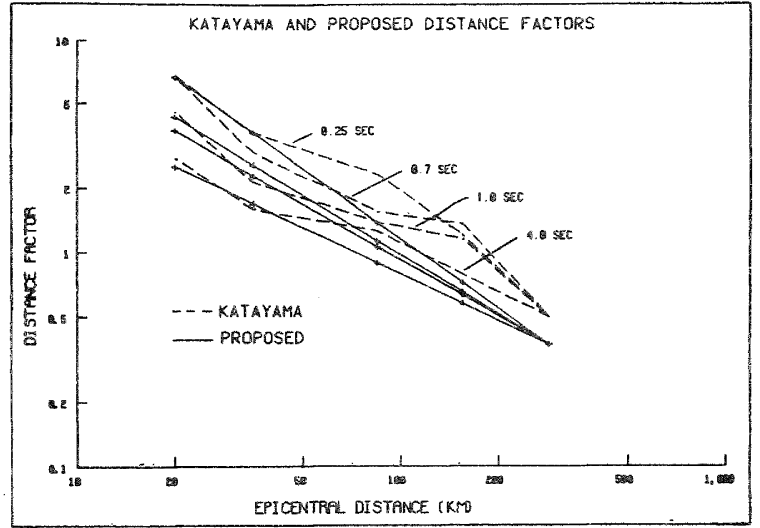

FIG. 5 : DISTANCE FACTORS OF THE KATAYAMA MODEL AND PROPOSED FACTORS TO GIVE MORE RAPID ATTENUATION.

0.25 seconds corresponding to the maximum of the 20-59 km distance factors rather than at the spectral period of zero corresponding to peak ground acceleration, which is not included in the Katayama model. The effective distance for each class was taken as the geometric mean of its limits, and $\gamma=-1.1$ attenuation at 0.25 seconds used to obtain the new constant distance factor for the 200-405 km class from the $20-59 \mathrm{~km}$ distance factor. Straight-line rays radiating from this new constant value back through the $20-59 \mathrm{~km}$ values for each spectral period were drawn on a loglog plot of distance factor versus distance (Fig. 5), corresponding to $D^{-\gamma}(T)$ attenuation, and the value for the distance classes read off at their geometric mean distances. Problems with the singularity of $D^{-\gamma(T)}$ as distance $D$ approaches zero were avoided by reading off the factors for $0-20 \mathrm{~km}$ at $20 \mathrm{~km}$.

obviously this treatment of the distance attenuation is rather arbitrary. However, it is based on the largest magnitude shallow New Zealand earthquake For which strong-motion data is available, and $D^{-\gamma}(T)$ attenuation with distance is a common assumption. It seemed a justifiable way of introducing more appropriate distance attenuation into the Katayama model. The overall result is a reasonably severe reduction of most of the distance factors, leading to much less contribution to the seismic hazard from distant events.

\subsection{Regional Variation of Attenuation}

In his study of the attenuation of intensities, Smith [23] found different behaviour. for the East Coast of the North Island ("Hawkes Bay") and Fiordland than for the rest of the country. There is insufficient response spectra data to study this problem, but an attempt can be made with peak accelerations.

For Hawkes Bay, the reduction in intensity from that expected for the rest of the country as found by Smith was a complicated function of magnitude and distance. The acceleration data was inconclusive in supporting the reductions shown by intensities. There were indications of higher accelerations at low magnitudes for the East Coast of the North Island, but less increase with magnitude leading to possibly lower accelerations at high magnitudes, but the approximate changeover level is about the magnitude at which data runs out. There were also indications of different behaviour between the south-western and north-eastern ends of the region, but insufficient data and insufficient accuracy in the estimates of the parameters of the attenuation models to be conclusive. It has been decided to treat this region in the same way as the rest of the country at present.

Intensities for Fiordland for a given magnitude and distance invariably fall below those expected elsewhere in the country. There are only 7 acceleration records for Fiordland, but the Fiordland data falls at substantially lower accelerations, with a mean residual for the $10_{10}$ acceleration of approximately -0.2 , or 10 a factor of 0.6 for the acceleration, than the rest of the data for the same magnitude and distance for a variety of fitted models, in line with the observed reduced intensities. The reduction in intensities $-\delta I$ for Fiordland was found to be

$$
-\delta I=M-4.5-\frac{D}{100}
$$

As a rough approximation, accelerations double with a unit change in intensity. and the same behaviour is assumed for spectral accelerations to obtain

$$
-\delta \overline{\log _{10} S A(T)}=0.3\left(M-4.5-\frac{D}{100}\right)
$$

This halves the spectral accelerations in Fiordland from those expected elsewhere for a magnitude $M$ of 6.5 at an epicentral distance $D$ of $100 \mathrm{~km}$.

\section{PROBABILISTIC ENHANCEMENT}

A feature which has had a considerable effect on the level of seismic hazard calculated in a number of New Zealand studies is a phenomenon referred to as "probabilistic enhancement".

The data from which attenuation relationships for strong-motion earthquake shaking are derived invariably show a large scatter about the mean relation, so it has become the fashion to express the attenuation formulae in probabilistic form. Usually the acceleration (or spectral acceleration) is assumed to be log-normally distributed, with the attenuation expression giving the mean of the log acceleration as a function of magnitude and distance. The standard deviation $\sigma \log 10 \mathrm{Z}$ is assumed independent of magnitud and distance, as for the Katayama model.

In seismic hazard analyses, much larger accelerations are often calculated for a given return period when the probabilistic form of the attenuation 
relations are used than when a "deterministic" approach is taken using the same mean relationship with no scatter. This increase arises because in the probabilistic model high levels of shaking are associated not only with the mean levels from rare large earthquakes, but also with the upper tail accelerations of much more common moderate magnitude events. This increase in the acceleration for a given return period, or the corresponding increase in mean occurrence rate for a given acceleration level, is referred to as "probabilistic enhancement". With the large scatter in strong-motion data, and the consequent large standard deviations of most attenuation relationships, this enhancement is often very severe.

As an example, take the case considered by Peek [19] of an unbounded magnitude model and a common form of attenuation model in which $\frac{10 g}{\log }$ varies linearly with magnitude, with standard deviation $\sigma$. The annual number of earthquakes per unit area exceeding magnitude $M$ is given by

$$
\log _{10} N(M)=a-b M
$$

and

$$
\overline{\log _{10} Z}=\mathrm{CM}+\alpha(\mathrm{D})
$$

In this case the probabilistic enhancement factors are independent of acceleration and return period. The factors are exp [2.3 $\exp \left[2.3^{2} \mathrm{~b} \sigma^{2} / 2 \mathrm{c}\right]$ for acceleration and $\exp \left[2.3^{2} b^{2} \sigma^{2} / 2 c^{2}\right]$ for occurrence rate. Figure 6 shows these factors plotted as a function of $\sigma$ for $a \mathrm{~b}$-value of 1.1 typical of New Zealand and a c-value of 0.25 , typical of many attenuation relations including Katayama's. Values of $\sigma$ in various studies vary between about 0.2 and 0.3 , corresponding to standard deviations of a factor of 1.6 and 2.0 respectively on $z$. As can be seen from the graphs, the probabilistic enhancements vary rapidly with $\sigma$ in this range. Obviously the correct value of this paremeter must be known to use the results with any confidence. Using the near upper bound value of 0.3 is

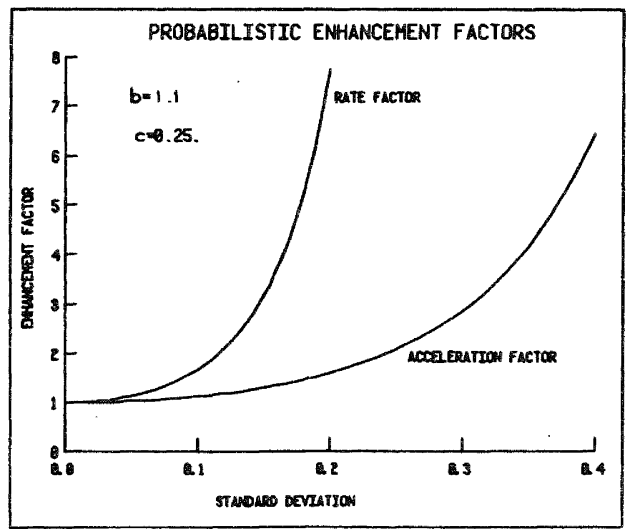

FIG. 6 : ENHANCEMENT FACTORS FOR PROBABILISTIC OVER DETERMINISTIC ATTENUATION MODEL FOR PARAMETERS TYPICAL OF NEW ZEALAND. overly conservative in many cases. The enhancement factors are also sensitive to the parameters $b$ and $c$, as seen from Table 3. For more realistic bounded magnitude seismicity models, the enhancement is not as severe, but still highly dependent on $\sigma$.

Unbounded accelerations are possible even with bounded magnitudes because of the log-normal acceleration distribution. This problem can be overcome by truncating the distribution of $\log z$, either at $\pm n \sigma$ or as a specified acceleration.

With the first option the choice of $n$ is arbitrary, often 2 or 3 . Truncating the distribution shows that much of the probabilistic enhancement comes from accelerations $2 \sigma$ or more above the median value.

In some cases for site specific studies it may be possible to specify an upper bound acceleration based on knowledge of the yield shear stress of the soil. This approach has been used recently to provide a possible explanation of an apparent maximum horizontal acceleration cut-off in very near-field accelerograms from the 1979 Imperial Valley earthquake [15].

Bender [1] discusses probabilistic enhancement in detail.

\section{SCALING OF SPECTRA TO DIFFERENT RETURN PERIODS OR PROBABILITIES OF EXCEEDANCE}

A problem which frequently arises in seismic risk or in selecting elastic response spectra for design is how to scale spectra for desired return periods or probabilities of exceedance. Peek and Mulholland determined the surprising result that the shape of the uniform risk spectra for New Zealand as a function of spectral period is virtually independent of return period and geographical location. The incorporation of the increased attenuation with distance or the truncation of the log-normal acceleration

distributions may alter this result, but it makes scaling of spectra very easy, in that only one spectral period need be considered to scale the whole spectra.

In what follows, $a$ or A refers to accelerations of some particular spectral period, which may be zero corresponding to peak ground accelerations. All references to $t$ or $T$ relate to return periods or durations, not spectral periods.

The results of the probabilistic seismic risk studies give accelerations as a function of return period $T, a(T)$, or conversely return periods as a function of acceleration $T(a)$. The return periods are the inverse of the mean rate of a Poisson Process. From the Poisson model

Probability $(A>a$ in time $t)=1-e^{-t / T(a)}$

The problem of finding the acceleration for a given probability of exceedance $p$ in time $t$ reduces to finding the equivalent return period $T$, and hence $a(T)$. Some 
simple manipulation leads to the required return period $\mathrm{T}$.

$$
T=\frac{t}{-\ln [1-p]}
$$

The return period $T(a)$ is usually given graphically. However it turns out that to a good approximation there is a linear relation between the logs of the acceleration and return period

$$
\log T=K\left[\log a-\log a_{1}\right]
$$

A plot of the return period relation $T(a)$ derived from Peek's study for the Haywards rock site in Wellington for the $5 \%$ damped response spectral acceleration at 0.20 seconds is shown in Fig. 7, which shows that the linear relation is valid for return periods longer than about 20 years. The fall-off of accelerations from the linear relation at shorter return periods is probably due to the truncation of magnitudes below 4.5 in the seismicity model.

The existence of such a simple linear relationship begs the question of whether it can be derived theoretically. For the simple attenuation and seismicity model given in the section on probabilistic enhancement, the relation becomes

$$
\log T(a)=\frac{b}{c} \log \frac{a}{a_{1}}
$$

The parameters $\mathrm{b}$ and $\mathrm{c}$ are the coefficients of the magnitude term in the seismicity and attenuation model respectively. Thus the parameter $\mathrm{K}=\mathrm{b} / \mathrm{c}$ governing scaling to other return periods is the same for deterministic and probabilistic models for this simple case.

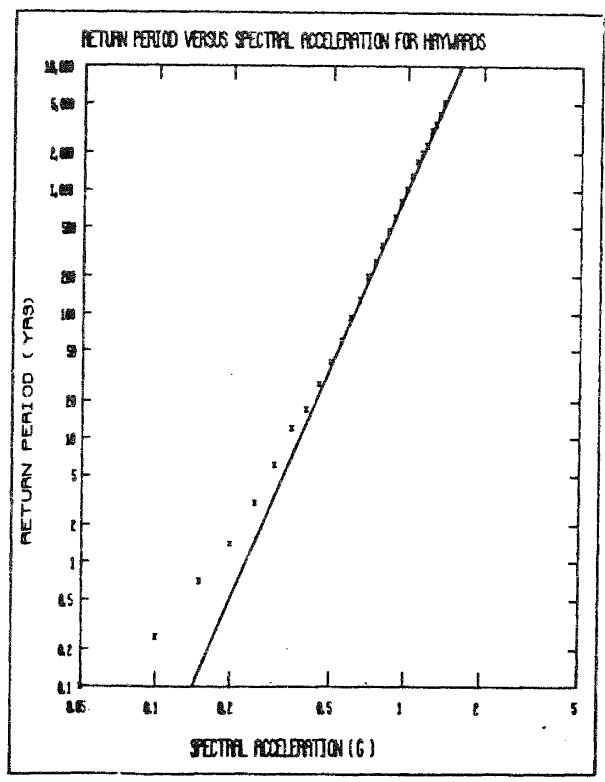

FIG. 7 : RETURN PERIOD FOR SA $(0.2$ SECOND, 5\% DAMPING), THE PEAK OF THE SPECTRA, FOR A ROCK SITE AT HAYWARDS BASED ON PEEK'S RESULTS, AND THE TYPE 2 EXTREME-VALUE FIT.
The standard deviation of the attenuation model affects only the characteristic value $a_{1}$, not the scaling of acceleration with return period.

The linear relation between $\log$ a and $\log T$ corresponds to a type II extreme value distribution [9] for the maximum acceleration in time $T$. The type II extreme value cumulative distribution function is

$$
F_{T}(a)=\exp \left[-\left(a_{T} / a\right)^{k}\right]=\exp \left[-T\left(a_{1} / a\right)^{k}\right]
$$

The characteristic value $a_{m}$ is the acceleration with return period $T$.

For this distribution, the coefficient of variation, that is the ratio of its standard deviation to its mean, is a function only of $\mathrm{K}$. The larger $\mathrm{K}$ the smaller the coefficient of variation.

For the more seismic regions of New Zealand such as Wellington, the value of $\mathrm{K}$ is about 4.7. This is about twice the value of 2.3 quoted for the United States in an NBS report [8], giving a much more rapid increase of return period with acceleration in New Zealand and also a much reduced coefficient of variation of the maximum acceleration in a given duration, 0.34 against 1.38. The larger $K$ value has the disadvantage however of making the probabilistic enhancement problem much more severe in New Zealand, as the enhancement factors are

$\exp \left[2.3^{2} \mathrm{~K}^{2} / 2\right]$ for acceleration and $\exp \left[2.3^{2} \mathrm{~K}^{2} \sigma^{2} / 2\right]$ for occurrence rate. The distributions of the maximum $5 \%$ damped spectral accelerations at 0.20 second natural period, the peak of the spectra, for Haywards are shown in Fig. 8 for $T$ equal to $1,50,100$ and 150 years. It is important to remember these broad spreads. which tend to be overlooked when the single-valued $T$-year acceleration is specified.

\section{SCALING OF SPECTRA FOR DIFFERENT}

The most commonly used approach to this problem is that used by Newmark and Hall [18] and Mohraz [16], who scale the constant acceleration, constant velocity and constant displacement portions of their design spectra as displayed by straight line segments on tri-partite plots by different factors, corresponding to a spectral period dependent scaling. A consideration of the 14 New Zealand spectra used in the comparison with the Katayama model suggests that the modification of the spectra with damping given by Newmark and Hall is considerably greater than that exhibited by New Zealand spectra. The mean of these 14 spectra for 2,5 and $20 \%$ damping is shown in Fig. 9. Research is in progress to determine appropriate scaling factors as a function of spectral period and damping for New Zealand spectra. 


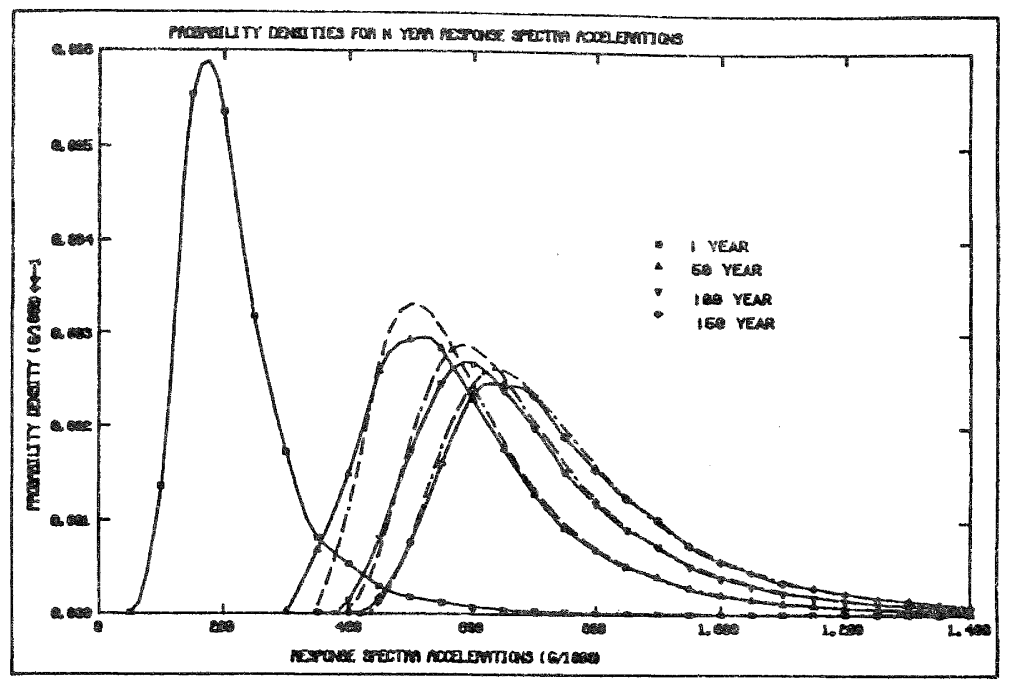

FIG. 8 : DISTRIBUTION OF MAXIMUM VALUES OF SA 10.2 SECOND, 5\% DAMPING) IN VARIOUS DURATIONS FOR RETURN PERIOD CURVE OF FIGURE 7 (SOLID LINE) AND TYPE 2 EXTREME-VALUE FIT (DASHED).

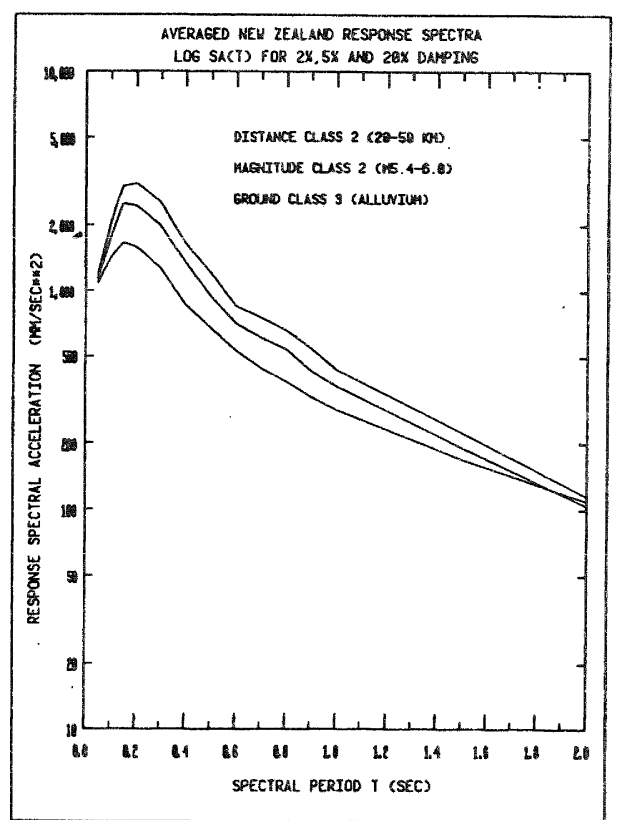

FIG. 9 : VARIATION OF MEAN RESPONSE SPECTRA WITH DAMPING FOR THE 14 NEW ZEALAND RECORDS OF TABLE 2 AND FIGURE 3.

\section{CONCLUSIONS}

Recent seismic hazard analyses in New Zealand have taken a more rational approach than in the past when design spectra were based on averaging a few of the strongest overseas spectra. Now detailed seismicity models are being combined with probabilistic attenuation models for response spectral accelerations to obtain uniform risk spectra with desired return periods. However, it must be recognised that despite the vastly improved methodology, there are still considerable uncertainties with both the seismicity and attenuation models.
The attenuation models must necessarily be based on overseas data because of insufficient New Zealand spectra to develop models based solely on local data. For moderate magnitudes $(5.4-6.0)$ and epicentral distances $(20-59 \mathrm{~km})$ on alluvial sites, corresponding to the largest class of New Zealand spectra. there is an excellent agreement between the average New Zealand spectrum and that predicted by a model derived from Japanese data by Katayama. Unfortunately, the amplitude of shaking for which this comparison was obtained is only about half that for the code-level 150 year return period in the more active areas of New Zealand. Moreover, there are uncertainties in the attenuation of shaking with distance, and in the correct value of the standard deviation required to represent the scatter in the strong-motion data.

Earthquake ground motion appears to attenuate much more rapidly with distance in New Zealand than Japan. The distance factors of the Katayama response spectral acceleration model have been modified quite considerably on the basis of scratchplate records of maximum ground accelerations in the Inangahua earthquake. This reliance on data from a single event and modification of spectral values on the basis of only ground acceleration values is unsatisfactory. A set of spectral acceleration data over a broad distance range is required for a major (magnitude 7 or greater) New Zealand earthquake to check this modification.

The probabilistic enhancement of the calculated seismic hazard is severe in New Zealand, and is very sensitive to the value of the standard deviation of the attenuation model and to the dependence of the seismicity and the strength of shaking on magnitude. This sensitivity is much greater is New Zealand than in the United States because large seismicity b values in New Zealand reduce the relative contribution of large magnitude events to the hazard. The standard deviation of the 
Katayama attenuation model has been reduced from 0.30 to 0.23 , in better agreement with New Zealand data and other overseas attenuation models. Berrill [6] has suggested and the SANZ Seismic Risk Committee had adopted a different perioddependent modification of the standard deviation. Strategies to overcome such unrealistic features as unbounded accelerations in the probabilistic attenuation model are being investigated.

A regional reduction of spectral accelerations has been introduced for Fiordland on the basis of studies of the attenuation of intensity supported by the few Fiordland ground acceleration records. The strong-motion instrumental data is inconclusive for the Hawkes Bay region where intensities suggest that the attenuation may also be different from the rest of the country, so no modification has been introduced for that region at present.

Scaling of spectra for different return periods is simplified by a nearly invariant shape for different return periods and regions of the country, and a nearly linear relationship between log acceleration and log return period. This linear relationship implies a type II extreme value distribution of maximum acceleration of given spectral period in a given,time. The increase in acceleration with return period is much less severe than in the US, again because of the high bvalues in New Zealand. This less rapid increase leads to a lower coefficient of variation (standard deviation/mean) of the extreme value distribution, but the spread is still large. The dependence of spectra on damping has not been investigated in detail for New Zealand, but the variation with damping appears much less than in US design spectra.

In summary, New Zealand data has been utilised as much as possible to verify and modify a model for attenuation of spectral accelerations. This has resulted in changes to the standard deviation of the model and to the rate of attenuation with distance, and in the introduction of a regional modification for Fiordland, all based on barely sufficient data. Spectra equivalent to the 150 year return period spectra for the more seismic areas of the country have still to be obtained for direct verification of the model at code-level amplitudes.

\section{REFERENCES}

(1) Bender, B. (1984). Incorporating Acceleration Variability into seismic Hazard Analysis. Bull. Seism Soc Am, Vol. 74, ppl451-62.

(2) Bentley, R.J. (1979). Average Estimates of the Attenuation with Distance of $5 \%$ Damped Horizontal Acceleration Response Spectra. Proc. 2nd South Pacific Regional Conference on Earthquake Engineering, wellington.
(3) Berrill, J.B. (1984). Seismic Hazard Analysis and Design Loads.

Proc. RRU Bridge Design Seminar, Auckland.

(4) Berrill, J.B., Priestley, M.J.N. and Chapman, H.E. (1980). Design Earthquake Loading and Ductility Demand. Bull. NZNSEE, Vol. 13, pp232-41.

(5) Berrill, J.B., Priestley, M.J.N. and Peek, R. (1981). Further Comments on Seismic Design Loads for Bridges. Bul1. NZNSEE, Vol. 14, pp3-11.

(6) Berrill, J.B. (1985). Distribution of Scatter in New Zealand Accelerograph Data. Bull. NZNSEE, Vol. 18, pp151-64.

(7) Cornell, C.A., Banon, H. and Shakal, A.F. (1979). Seismic Motion and Response Prediction Alternatives. Eq. Eng. and Struct. Design, Vol. 7, pp295-315.

(8) Ellingwood, B. et al (1980). Development of a Probability Based Load Criterion for American National Standard A58. Building Code Requirements for Minimum Design Loads in Buildings and other structures. NBS Special Publication 577. US Department of Commerce, National Bureau of Standards.

(9) Gumbel, E.J. (1958). Statistics of Extremes. Columbia University Rress, New York.

(10) Joyner, W.B. and Boore, D.M. (1981). Peak Horizontal Acceleration and Velocity from Strong-Motion Records Including Records from the 1979 Imperial Valley, California, Earthquake. Buill. Seism Soc Am., vol. 71, pp2011-38.

(11) Katayama, T. (1982). An Engineering Prediction Model of Acceleration Response Spectra and its Application to Seismic Hazard Mapping. Eq Eng and Struct Design, Vol 10, ppl49-63.

(12) McGuire, R.K. (1974). Seismic Structural Response Risk Analysis Incorporating Peak Responses, Regressions on Earthquake Magnitude and Distance. Dept of Civil Eng Research Report R74-5I, MIT, Cambridge, Massachusetts.

(13) Matuschka, T. (1980). Assessment of Seismic Hazards in New Zealand. Report No. 222, Dept of Civil Eng, University of Auckland.

(14) Ministry of Works and Development (1981). Recommendations for the Seismic Design of Petrochemical plants.

(15) Mohammadioun, B. and Pecker, A. (1984) Low-frequency Transfer of Seismic Energy by Superficial Soil Deposits and Soft Rocks. Eq Eng and struct Design, Vol. 12, pp537-64. 
(16) Mohraz, B. (1976). A study of Earthquake Response Spectra for Different Geological Conditions. Bul1 Seism Soc Am, Vol. 66, pp915-35.

(17) Mulholland, W.M. (1984). Estimation of Design Earthquake Motions for New Zealand. Research Report 82-9, Dept of Civil Eng, University of Canterbury.

(18) Newmark, N.M. and HaI1, W.J. (1969) Seismic Design Criteria for Nuclear Reactor Facilities. Proc. 4th World Conf. Eq Eng, Session B4, pp 37-50.

(19) Peek, R. (1980). Estimation of Seismic Risk for New Zealand. A Seismicity Model and Preliminary Design Spectra. Research Report 80-21, Dept of Civil Eng, University of Canterbury.

(20) Peek, R., Berrill, J.B. and Davis, R.O. (1980). A Seismicity Model for New Zealand, Bull NZNSEE, Vol. 13, pp 355-64.

(21) Priestley, M.J.N. and Park, R. (1984). Strength and Ductility of Bridge Substructures. Road Research Unit, Bulletin 71, National Roads Board, Wellington.

(22) Skinner, R.I. (1964). Earthquake= Generated Forces and Movements in Tall Buildings. Bulletin 166, New Zealand Department of Scientific and Industrial Research.

(23) Smith, W.D. (1978). Spatial Distribution of Felt Intensities for New Zealand Earthquakes. NZ J Geol and Geophys, Vol. 21, pp293-311.

(24) Smith, W.D. (1982). Pitralis in the Estimation of Seismic Hazard. Bul1 NZNSEE, Vol. 15, pp77-81.

(25) Smith, W.D. and Berryman, K.R. (1983). Revised Estimates of Earthquake Hazard in New Zealand. Bull NZNSEE, Vol. 16, pp259-72.

(26) Smith, W.D. and Berryman, K.R. (1984). Earthquake Hazard in New Zealand:

Inferences from Seismology and Geology. Recent Crustal Movements Symposium, Victoria University, Wellington.

(27) Trifunac, M.D. and Anderson, J.G. (1977). Preliminary Empirical Models for Scaling Absolute Acceleration Spectra. Report No. CE77-03, Dept. of Civil Eng, University of Southern California, Los Angeles. 